\title{
Electroconvulsive therapy, practice and evidence ${ }^{\dagger}$
}

Allan I. F. Scott

\section{Summary}

This issue includes the findings from the largest randomised controlled trial ever conducted with bilateral, unilateral and bifrontal electroconvulsive therapy (ECT). The background to the study and its findings are discussed.

\section{Declaration of interest}

A.I.F.S. was the Editor of the guidelines on ECT that were published by the Royal College of Psychiatrists in The ECT Handbook (2nd edn).
Allan I. F. Scott is a consultant in general adult psychiatry at the Royal Edinburgh Hospital, where he also works in the ECT clinic.

In 1981, the British Journal of Psychiatry published a review of electroconvulsive therapy (ECT) that was widely cited for the rest of that decade. ${ }^{1}$ The author was the late Professor Robert (Bob) Kendell, an eminent psychiatrist and a future president of the Royal College of Psychiatrists. He noted that ECT was already in widespread use before the randomised controlled trial was introduced into clinical medicine. Nevertheless, he concluded that the available evidence for its efficacy in depressive illness was strong, and that it acted much faster than drugs. He also made a number of recommendations about the administration of ECT, including the preferred electrode placement. It was well established that any memory impairment caused by ECT was less severe and more short-lived when given unilaterally over the nondominant hemisphere (usually the right side of the head); he therefore recommended unilateral ECT.

\section{Practice}

Kendell also observed that, in his own words, 'a bewildering variety of different electrode placements' had been used over the years. ${ }^{1}$ One experimental placement that had interested ECT practitioners over the decades was bifrontal ECT. The electrodes are placed, not over each temple as in standard bilateral ECT, but further forward on the forehead, above the outer canthus of each eye. The aim was to avoid direct electrical stimulation of the temporal lobes thought to be involved in the recall of memories. The hope was that bifrontal ECT would have the cognitive advantages of unilateral ECT, but retain the efficacy of standard bilateral ECT. This hope has never been assessed adequately in a randomised controlled trial.

The use of ECT fell dramatically in the two decades after his review. The fall was welcomed in the UK because it was taken as a sign that alternative and effective treatments for depressive illness were becoming more available. ${ }^{2}$ Psychiatrists who still prescribed ECT over those two decades did not prefer unilateral ECT. The vast majority of treatments were bilateral. In this decade, first the American Psychiatric Association $(\mathrm{APA})^{3}$ and then the Royal College of Psychiatrists ${ }^{4}$ urged that unilateral ECT be used more, for the same reasons given by Kendell. However, today's prescribers still favour bilateral ECT; some clinics simply never

†See original paper, pp. 226-234, this issue. give unilateral ECT. ${ }^{5}$ A recent survey in Scotland found that there was little doubt among prescribers that unilateral ECT reduced the burden of adverse effects, but they thought bilateral ECT was more efficacious. ${ }^{6}$

\section{Evidence}

Kendell sounded exasperated by what he called innumerable and repetitive comparisons of unilateral and bilateral ECT. There was no significant difference in efficacy, although he conceded that the average course of unilateral ECT was a little longer.

In 2001 the Department of Health in England commissioned a systematic review of the efficacy of ECT using the modern methods of evidence-based medicine. The efficacy of ECT was clearly confirmed in the short-term treatment of depressive illness. ${ }^{7}$ The findings from 22 controlled comparisons of unilateral and bilateral ECT between 1965 and 2000 were also appraised; bilateral ECT was found to be more efficacious with the caveat that the electrical dose may be a confounding factor in the comparison. The APA had already noted that the efficacy of unilateral ECT may depend on the electrical dose. ${ }^{3}$ It was persuaded that when unilateral ECT was given with an electrical dose six times the seizure threshold, then it was fully equivalent to bilateral ECT. But proponents of bilateral ECT were not convinced. They argued that the existing controlled comparisons were only small scale, and lacked the statistical power to conclude confidently that the two were equivalent. There were also documented cases of patients with depression who had failed to improve with unilateral ECT but did recover subsequently with bilateral ECT; this included patients originally treated with high-dose unilateral ECT. A proper comparison was needed.

Electroconvulsive therapy was also in widespread clinical use well before the development of safe techniques to study the function of the living human brain. Modern brain imaging has established that the so-called generalised cerebral seizure is a misnomer; the seizure does not involve the whole brain homogenously. It turned out that the way in which the seizure was induced in ECT had a substantial bearing on its generalisation as assessed by the specific regions of the brain involved. ${ }^{8}$ It was entirely plausible that there were differences both in efficacy and adverse effects among the different electrode placements.

\section{The latest evidence}

The present issue of the Journal includes the findings from the largest randomised controlled trial ever conducted to compare the efficacy and cognitive effects of the three electrode placements, 
which were given with the electrical doses recommended today. ${ }^{9}$ The cognitive effects were measured using a comprehensive array of tests. Electroconvulsive therapy was given, as is customary in the USA, three times each week. Although keenly anticipated, the findings will also be a disappointment to many readers.

The researchers should first be commended for collaboration among five sites in the USA, conducted without any commercial sponsorship. Despite the 5 years of endeavour, too few patients were recruited to make confident comparisons. The evidence is still the best we have. How will the findings affect clinical practice?

A proponent of bilateral ECT may say 'I told you so', and carry on as before. Bilateral ECT worked more quickly than the other placements with a rapid and robust antidepressant effect. A word of caution is necessary. The most distressing adverse effect of ECT is the loss, sometimes permanent, of autobiographical memories. The strongest predictor of whether or not retrograde amnesia will occur in the first few months after a course of ECT is the use of the bilateral placement. ${ }^{10,11}$

A proponent of unilateral ECT may be disappointed that it did not reduce depressive symptoms as quickly as bilateral ECT, much as Kendell had hinted 30 years ago. Another disappointment may be the confirmation that the immediate cognitive effects of unilateral ECT are, like its efficacy, related to the electrical dose. After the first unilateral treatment, given at a threshold dose, patients became reoriented more quickly than after bilateral ECT. This advantage was lost at the second treatment, when the electrical stimulus was increased to the treatment dose of six times the threshold. An important caveat must be noted. The time it took for patients to regain full orientation was not measured in the present study. It is already known that the use of a unilateral placement substantially reduces the risk of prolonged disorientation after ECT. ${ }^{4}$ The use of unilateral ECT may be important for individual patients prone to the cognitive effects of ECT. It is also true that the prescription of a unilateral placement is the single most important step to minimise the risk of retrograde amnesia after ECT.

There are no words of consolation for the proponents of bifrontal ECT. It worked more slowly than standard bilateral ECT and its cognitive effects were more marked. Certainly it led to more impairment of verbal learning and there was no suggestion it would cause less impairment of the recall of autobiographical memories. The authors concluded conservatively that it should remain only as an experimental treatment. It could be argued just as well that the study found no justification for the use of bifrontal ECT. Those who originally proposed this placement 40 years ago did so without evidence of the regions of the brain that are active in the recall of memories. In healthy individuals, the recall of episodic autobiographical memories involves a complex network that includes the prefrontal, medial and lateral temporal cortices. ${ }^{12}$ The preferential electrical stimulation of the rostral part of this network seems unlikely to prevent the impairment of this recall.

\section{The synthesis of practice and evidence}

There is no ideal electrode placement for ECT. When the rate of clinical improvement and completeness of response have priority, then bilateral electrode placement is preferable. When minimising the risk of cognitive adverse effects has priority, then unilateral electrode placement is preferable. Both the APA and the Royal College of Psychiatrists have recommended that the selection of the original electrode placement should, where possible, be part of the process of informed consent for ECT., There is no objection at all to the switch of electrode placement during the course of treatment.

The present study contained a notable finding about the place of ECT in contemporary psychiatric practice. The overall remission rate with ECT in the intention-to-treat analysis was $60 \%$. When ECT is used to treat unipolar major depression that has already failed to remit with vigorous antidepressant treatment, then the remission rate is still about $50 \% .{ }^{13}$ The patients in the present study had already been ill for an average of 2.4 years (Table 2). ${ }^{9}$ Why did they have to wait so long to be offered such an efficacious treatment?

Allan I. F. Scott, MD, FRCPsych, Royal Edinburgh Hospital, Morningside Park, Edinburgh, EH10 5HF, UK. Email: Fiona.J.Morrison@nhslothian.scot.nhs.uk

First received 3 Dec 2009, accepted 15 Jan 2010

\section{References}

1 Kendell RE. The present status of electroconvulsive therapy. Br J Psychiatry 1981; 139: 265-83.

2 Eranti SV, McLoughlin DM. Electroconvulsive therapy - state of the art. Br J Psychiatry 2003; 182: 8-9.

3 Committee on Electroconvulsive Therapy. The Practice of Electroconvulsive Therapy: Recommendations for Treatment, Training and Privileging. American Psychiatric Association, 2001

4 Scott A (ed). The ECT Handbook (2nd edn). Gaskell, 2005

5 Scottish ECT Accreditation Network. Annual Report 2009: Reporting on 2008. NHS National Services Scotland, 2009

6 Brown KA. Unilateral and bilateral electroconvulsive therapy: what informs Scottish psychiatrists' choices? Psychiatr Bull 2009; 33: 95-8.

7 The UK ECT Review Group. Efficacy and safety of electroconvulsive therapy in depressive disorders: a systematic review and meta-analysis. Lancet 2003; 361: 799-808

8 Enev M, McNally KA, Varghese G, Zubal IG, Ostroff RB, Blumenfeld H. Imaging onset and propagation of ECT-induced seizures. Epilepsia 2007; 48: 238-44.

9 Kellner $\mathrm{CH}$, Knapp R, Husain MM, Rasmussen K, Sampson S, Cullum M, et al. Bifrontal, bilateral and right unilateral electrode placement in ECT: randomised trial. Br J Psychiatry 2010; 196: 226-34.

10 Lisanby SH, Maddox JH, Prudic J, Devanand DP, Sackeim HA. The effects of electroconvulsive therapy on memory of autobiographical and public events. Arch Gen Psychiatry 2000; 57: 581-90.

11 Sackeim HA, Prudic J, Fuller AR, Keilp J, Lavori PW, Olfson M. The cognitive effects of electroconvulsive therapy in community settings. Neuropsychopharmacology 2007; 32: 244-54.

12 Piolino P, Desgranges B, Eustache F. Episodic autobiographical memories over the course of time: cognitive, neuropsychological and neuroimaging findings. Neuropsychologia 2009; 47: 2314-29.

13 Dombrovski AY, Mulsant BH, Hasket RF, Prudic J, Begley AE, Sackeim HA. Predictors of remission after electroconvulsive therapy in unipolar major depression. J Clin Psychiatry 2005; 66: 1043-9. 